\title{
Rates of morphological evolution in Captorhinidae: an adaptive radiation of Permian herbivores
}

\author{
Neil Brocklehurst Corresp. 1 \\ 1 Museum für Naturkunde, Leibniz-Institut für Evolutions- und Biodiversitätsforschung, Berlin, Germany \\ Corresponding Author: Neil Brocklehurst \\ Email address: neil.brocklehurst@mfn-berlin.de
}

The evolution of herbivory in early tetrapods was crucial in the establishment of terrestrial ecosystems, although it is so far unclear what effect this innovation had on the macro-evolutionary patterns observed within this clade. The clades that entered this under-filled region of ecospace might be expected to have experienced an "adaptive radiation": an increase in rates of morphological evolution and speciation driven by the evolution of a key innovation. However such inferences are often circumstantial, being based on the coincidence of a rate shift with the origin of an evolutionary novelty. The conclusion of an adaptive radiation may be made more robust by examining the pattern of the evolutionary shift; if the evolutionary innovation coincides not only with a shift in rates of morphological evolution, but specifically in the morphological characteristics relevant to the ecological shift of interest, then one may more plausibly infer a causal relationship between the two.

Here I examine the impact of diet evolution on rates of morphological change in one of the earliest tetrapod clades to evolve high-fibre herbivory: Captorhinidae. Using a method of calculating heterogeneity in rates of discrete character change across a phylogeny, it is shown that a significant increase in rates of evolution coincides with the transition to herbivory in captorhinids. The herbivorous captorhinids also exhibit greater morphological disparity than their faunivorous relatives, indicating more rapid exploration of new regions of morphospace. As well as an increase in rates of evolution, there is a shift in the regions of the skeleton undergoing the most change; the character changes in the herbivorous lineages are concentrated in the mandible and dentition. The fact that the increase in rates of evolution coincides with increased change in characters relating to food acquisition provides stronger evidence for a causal relationship between the herbivorous diet and the radiation event. 
Herbivores

${ }^{1}$ Museum für Naturkunde, Leibniz-Institut für Evolutions- und Biodiversitätsforschung,

11 Corresponding Author: Neil Brocklehurst, neil.brocklehurst@mfn-berlin.de, +493020938306

12

13 


\section{Abstract.}

The evolution of herbivory in early tetrapods was crucial in the establishment of

terrestrial ecosystems, although it is so far unclear what effect this innovation had on the macro-

evolutionary patterns observed within this clade. The clades that entered this under-filled region

31 of ecospace might be expected to have experienced an "adaptive radiation": an increase in rates

32 of morphological evolution and speciation driven by the evolution of a key innovation. However

33 such inferences are often circumstantial, being based on the coincidence of a rate shift with the

34 origin of an evolutionary novelty. The conclusion of an adaptive radiation may be made more

35 robust by examining the pattern of the evolutionary shift; if the evolutionary innovation

coincides not only with a shift in rates of morphological evolution, but specifically in the

morphological characteristics relevant to the ecological shift of interest, then one may more plausibly infer a causal relationship between the two.

Here I examine the impact of diet evolution on rates of morphological change in one of

40 the earliest tetrapod clades to evolve high-fibre herbivory: Captorhinidae. Using a method of

41 calculating heterogeneity in rates of discrete character change across a phylogeny, it is shown

42 that a significant increase in rates of evolution coincides with the transition to herbivory in captorhinids. The herbivorous captorhinids also exhibit greater morphological disparity than

44 their faunivorous relatives, indicating more rapid exploration of new regions of morphospace. As

45 well as an increase in rates of evolution, there is a shift in the regions of the skeleton undergoing

46 the most change; the character changes in the herbivorous lineages are concentrated in the 
47 mandible and dentition. The fact that the increase in rates of evolution coincides with increased

48 change in characters relating to food acquisition provides stronger evidence for a causal

49 relationship between the herbivorous diet and the radiation event.

51 Key Words: Captorhinidae; Adaptive Radiation; Herbviore; Paleozoic; Tetrapod

\section{Introduction}

The evolution of high fibre herbivory represents a major step in the establishment of

57 terrestrial ecosystems. Prior to the appearance in the Pennsylvanian of tetrapods capable of

58 feeding directly on plant matter, the vast majority of primary consumers in the terrestrial realm are thought to have been detritivorous invertebrates (Shear \& Sheldon, 2001). By the end of the Cisuralian, five tetrapod lineages had independently evolved a herbivorous diet and terrestrial ecosystems were adopting a more modern set of tropic interactions, with a great abundance of

62 large terrestrial vertebrates supporting a relatively small number of macro-carnivores (Olson 63 1966; Sues \& Reisz 1998). Although arthropod herbivores were present in terrestrial ecosystems prior to the evolution of herbivory in tetrapods, evidence both of body fossils and feeding damage to plants is rare (Labandeira 1998, 2007, Shear 2000). In a review of the Carboniferous flora of Mazon

67 Creek, Scott \& Taylor (1983) found only 4\% showed any sign of having been bitten or chewed by arthropods. Terrestrial vertebrate herbivores were entering a somewhat under-filled region of ecospace, facing little competition. These early herbivores therefore provide an ideal opportunity 
70 to examine the changes in rate and mode of evolution and diversification resulting from

71 evolutionary innovations. Simpson's adaptive radiation model (Simpson 1953) refers to the rapid

72 emergence from a common ancestor of many species, coinciding with both ecological and

73 phenotypic divergence of the descendants. Simpson posited that a "key" evolutionary novelty

74 gives a lineage a selective advantage or allows it to enter a new ecological niche and thus leads

75 to an increase in morphological diversification or speciation rates. Such a model is often invoked

76 when analyses of diversification rate heterogeneity identify shifts that coincide with an

77 innovation of interest (e.g. Benson \& Choiniere 2013; Cook \& Lessa 1998; Forest et al. 2007;

78 Kazancioğlu et al. 2009; Kozak et al. 2005; McLeish et al. 2007; Ruber et al. 2003; Vences et al. 79 2002).

80 Since this seminal work, a substantial number of studies have refined our understanding

81 of the evolutionary processes behind adaptive radiations. It has now been acknowledged that

82 adaptive radiations do not necessarily require rapid speciation (Neige et al. 2013; Givnish 2015;

83 Simões et al. 2016); increases in rates of morphological diversification may take place in the

84 absence of increases in species richness and rates of speciation. The concept of the "key

85 innovation", critical to Simpson's model, has come under scrutiny. Often these innovations are

86 not a single trait, but instead a stepwise acquisition of traits or co-option of existing traits for a

87 novel purpose (exaption) that allows the entry into a new region of ecospace (Donoghue 2009;

88 Simões et al. 2016). Thus, the radiation may not coincide with the acquisition of a relevant trait

89 (Lieberman 2012). Models of radiations dependant on diversity and abundance have been

90 examined: colonists of new or depopulated adaptive landscapes where there is little competition

91 would maximise selection for divergence (Givnish 2010, 2015). By extension, as the radiation

92 fills the new region of ecospace, the rate of diversification should slow: an early burst model 
93 (Blomberg et al. 2003). However, examination of empirical data has produced conflicting results

94 regarding the ubiquity of an early burst model: Harmon et al (2010) suggested that early bursts

95 were rare when examining size and shape data, but when examining discrete character data

96 Hughes et al. (2013) found early peaks in disparity followed by diversification slow-downs or

97 decreases were the norm.

98 The inference of a causal relationship between innovation and shift in diversification rate

99 is in most cases circumstantial, based solely on the coincidence of the shift and the evolutionary

100 novelty. In order to more reliably infer a causal relationship, one must also examine the precise

101 nature of the shift. For example, Brocklehurst et al. (2015) showed that, although early amniotes

102 do exhibit lineage diversification rate increases coinciding with various "key" innovations, the

103 shifts did not represent increases in speciation rate but instead coincided with periods of

104 increased extinction rate. Thus, it was inferred that these innovations did not cause Simpsonian

105 adaptive radiations, but instead buffered against high levels of extinction.

106 In the same way, when attempting to infer a causal relationship between a key innovation

107 and a shift in rates of morphological evolution, it is not enough to point to a rate shift along the

108 branch where the innovation appeared, but one must examine the morphological changes

109 occurring subsequent to the shift; is the clade of interest showing a higher rate of changes in

110 features relevant to the exploitation of the new ecological niche allowed by the key innovation?

111 If not, there is unlikely to be a causal link between the two.

112 This logic is here applied to an examination of rates of morphological evolution in the

113 earliest herbivores, using the family Captorhinidae as a case study. Captorhinids were a diverse

114 clade of sauropsids (reptile-line amniotes) that appeared during the Late Pennsylvanian (Müller

$115 \&$ Reisz 2005) and survived until the end of the Permian. Herbivorous members of this clade 
116 appear in the Kungurian, characterised by the multiple rows of teeth and a propalineal motion of

117 the lower jaw in order to grind and shred plant matter (Dodick \& Modesto 1995; Modesto et al.

118 2007). In this paper, I examine the rates of morphological evolution in this family using a

119 method incorporating a time calibrated phylogeny and a matrix of discrete characters (Lloyd et

120 al. 2012). Emphasis is placed not only on examining whether rate increases coincide with shifts

121 in diet, but also on examining whether a shift in diet coincides with increased frequency

122 character-state transformation in regions related to feeding, such as the dentition. In this way, a

123 more robust inference may be made concerning the possibility of an adaptive radiation

124 coinciding with the origin of herbivory in this family.

125

126

127 Materials and Methods

128

Phylogeny and time calibration

130

The phylogeny used was that presented in Liebrecht et al. (2016), currently the most

131 comprehensive cladistic analysis of captorhinids. The phylogeny was time calibrated in the $\mathrm{R}$

132 3.1.2 (R Core Team 2014) using the method proposed by Lloyd et al. (2016), itself an expansion

133 of a method put forward by Hedman (2010). The method of Hedman (2010) was intended to

134 infer confidence intervals on the age of a specific node in the tree. It is a Bayesian approach

135 using the ages of successive straigraphically consistent outgroup taxa relative to the age of the

136 node of interest to make inferences about the quality of sampling; large gaps between the age of

137 the node of interest and that of the outgroups implies a poorly sampled fossil record, and

138 therefore the age of the node of interest may be inferred to be older. Lloyd et al. (2016) designed 
139 a procedure whereby this approach could date an entire tree rather than just a specific node. In

140 applying this method, successive outgroups are required to the total clade. The outgroups to

141 Captorhinidae employed were: Paleothyris and Hylonomus (found to be the outgroups to

142 Captorhinidae in the Bayesian analyses of Müller \& Reisz [2005]), Archaeothyris (the earliest

143 known synapsid [Reisz et al. 1972]), and Westlothiana (a reptiliamorph outside the amniote

144 crown according to Ruta \& Coates [2007]). A maximum age constraint was set as 334.7 million

145 years ago, the oldest reliable estimate using molecular dating for the origin of Amniota published

146 within the last five years at the moment of data collection (Parfrey et al. 2011).

147 Uncertainty surrounding the ages of taxa was accounted for using the method of Pol and

148 Norrell (2006). For each taxon (including the outgroups), 100 first appearances and last

149 appearances were drawn at random from a uniform probability distribution covering the full

150 possible range of ages for that taxon. 100 time-calibrated trees were produced from the 100 sets

151 of ages.

152 Since the analysis of Liebrecht et al. (2016) produced two most parsimonious trees

153 (MPTs), half the time calibrated trees were based on the first, and half on the seconds. All

154 analyses described below were carried out on all 100 of these trees. All 100 of these trees are

155 available in supplementary data 1 , and the age ranges allowed for each taxon in supplementary

156 data 2.

157

158 Reconstruction of dietary evolution

159 A dietary character with three states, carnivore, herbivore and omnivore, was scored for

160 all taxa present in the phylogeny. Ancestral character states were deduced using conditional

161 (joint) likelihood, employing the ace function in the ape package (Paradis et al. 2004) in R. This 
162 function allow three models of discrete character change: an equal rates model (transitions

163 between all states in all directions are equally probable), a symmetrical model (transitions

164 between two character states occur with equal probability in either direction, but different pairs

165 of character states have different probabilities of transition) and an all-rates-different model

166 (each transition has a different probability). In order to deduce which model was best for the data

167 available, these models were fit to the captorhinid phylogeny using likelihood methods,

168 employing the fitDiscrete function in the R package geiger (Harmon et al. 2008). The Akaike

169 weights were used to deduce the best fitting model.

170 Since this likelihood ancestral state reconstruction produced uncertain results surrounding

171 the character state at three nodes (see below), an alternative Bayesian approach for optimizing

172 the dietary character at these nodes was used as an independent test in the program Bayes Traits

173 V2 (Barker et al. 2007). A reversible jump Markov chain Monte Carlo (RJ MCMC) approach is

174 used to reconstruct the ancestral states of the discrete character, allowing different combinations

175 of character states to have different transition rates. The analysis was run for $10,000,000$

176 iterations with 100,000 discarded as burn-in, sampling every 1000 generations. These results are

177 presented in the electronic supplement, and the analyses described below are based on the

178 likelihood results.

179

180

Analysis of Rate Variation

181 Analysis of rate variation was carried out using the method of Lloyd et al. (2012), later

182 refined by Brusatte et al. (2014) and Close et al. (2015). Discrete morphological character scores

183 may be taken from the matrices used in cladistic analyses, and ancestral states are deduced using

184 likelihood. This allows the number of character changes along each branch to be counted, and 
185 rates of character change are calculated by dividing the number of changes along a branch by the

186 branch length. The absolute value calculated for the rate of each branch, however, can be

187 misleading due to the presence of missing data (Lloyd et al. 2012). As such it is more useful to

188 identify branches and clades where the rates of character change are significantly higher or lower

189 than others, rather than comparing the raw numbers. This is assessed by comparing two models

190 using a likelihood ratio test, one where the rates of change are uniform across the whole tree and

191 one where the branch of interest has a different rate to the rest of the tree. A similar method is

192 used to compare rates of evolution through time and identify bins where rates of evolution are

193 significantly high or low.

194 The character data used is from the matrix of Liebrecht et al. (2016). The time bins used

195 to examine rate variation through time were substages, dividing the international stages into two

196 bins, early and late. The analysis was carried out in R using functions from the package Claddis

197 (Lloyd 2016) on all 100 of the time calibrated trees. The data matrix is presented in

198 supplementary data 3.

199 Due to the uncertainty surrounding the optimisation of the dietary character, a stochastic

200 mapping approach was used to examine rate heterogeneity in the different dietary classes. For

201 each of the 100 time calibrated trees, the dietary character containing three states (carnivore,

202 omnivore and herbivore) was mapped onto the tree using likelihood. Using the character state

203 probabilities identified at each node, 100 possible evolutionary histories of diet in that tree were

204 generated for each of the 100 phylogenies following the procedure outlined by Bollback (2006),

205 giving a total of 10,000 stochastic maps. The mean rate of herbivorous branches, carnivorous

206 branches and omnivorous branches were calculated in each stochastic map, along with the mean 
207 rate of a randomly selected set of branches with a sample size equal to the number of

208 herbivorous branches in that map.

209 Taxonomic jack-knifing was used as a sensitivity analysis to examine the robusticity of

210 the results. In each iteration, three randomly selected taxa (the maximum number that could be

211 deleted leaving at least one member of each dietary regime) were dropped prior to running the

212 analyses of rate variation described above.

213

214 Disparity

215 The character matrix of Liebrecht et al. (2016) was also used to examine morphological

216 diversity (disparity). Morphological distances between taxa were calculated using the Maximum

217 Observable Rescaled Distance (MORD) distance measure of Lloyd (2016), which was shown to

218 perform better in datasets with large amounts of missing data. Following the suggestion of

219 Brusatte et al. (2008), the internal nodes of the phylogeny were treated as data points, with their

220 character scores inferred using ancestral state reconstruction, in order to account for the

221 incomplete sampling of the fossil record; these data points represent ancestral taxa that may have

222 possessed character combinations not observed in sampled taxa.

223

Having generated a distance matrix, once again the stochastic mapping approach was

224 used to compare disparity in different dietary classes. For each of the 10,000 evolutionary

225 histories generated, each taxon (both tip and node) was assigned a dietary class, and the mean

226 MORD distance for each of the three dietary classes was calculated.

227 Disparity through time was investigated by subjecting the MORD distance matrices to a

228 principal coordinate analysis. Disparity in each time bin was calculated as the sum of variances

229 of the PC scores of each taxon in that bin. An attempt was also made to incorporate both ghost 
230 lineages and internal branches into the analysis using a novel method illustrated in Figure 1.

231 Taxon $\mathrm{A}$ is present in time bin 3 , and its ancestral node is inferred to be in time bin 1 . Therefore

232 there must be a ghost lineage present in time bin 2 (Fig. 1a), which would be ignored in the

233 disparity analysis under the method of Brusatte et al. (2011), wherein only node and tip

234 morphologies were included. The morphology inferred in time bin 2 will depend on which model

235 of evolution is preferred; under a gradualistic model of evolution, assuming no change in rate

236 along the branch (Fig. 1b), the principal coordinate score in time bin 2 may be inferred by

237 calculating the rate of change in the principal coordinate along that branch, and the amount of

238 time between the ancestral node and the midpoint of time bin 2 . Alternatively one may assume a

239 punctuated model of evolution, where the morphological change occurs rapidly at the time of

240 speciation in time bin 1, and the lineage experiences morphological stasis for the remaining time;

241 thus the PC scores inferred in time bin 2 will be identical to that of the tip in time bin 3 (Fig. 1c).

242 Both methods are used here to compare the results. Again, the stochastic mapping approach was

243 used to assign a diet to each branch, allowing the comparison of patterns of disparity through

244 time in each of the dietary regimes. The function used to infer trait disparity through time while

245 including ghost lineages is presented in Supplementary data 5.

247 Lineage density

248 Sidlauskas (2008) highlighted that rate heterogeneity is not the only means by which

249 different clades may have different disparities. The "efficiency" with which the taxa explore

250 morphospace will also have an influence. A clade which continually returns to the same region

251 of morphospace will exhibit a lower disparity than a clade that explores novel regions of

252 morphospace, even if the rates of morphological change do not vary (Sidlauskas 2008). In fact, it 
253 has been observed that increased disparity can occur even alongside decreases in evolutionary

254 rates; when examining the evolution of mammals across the Cretaceous/Paleogene boundary,

255 Slater (2013) demonstrated that, although rates of body size evolution were lower after the

256 boundary, an increase in variance was possible due to the release of evolutionary constraint.

a measure of the amount of evolutionary change within a clade relative to the area of

259

morphospace explored. It is calculated by dividing the sum of the morphometric branch lengths

within a clade by the volume of the $95 \%$ confidence hyperellipsoid or convex hull of the clade's

morphospace. A lower lineage density indicates that the taxa are exploring novel regions of

morphospace rather than continuously returning to the same morphologies.

264 lineage density. For each of the 10,000 dietary histories generated by stochastic mapping, the

265 branch lengths within each dietary regime were calculated as the Euclidean distance between

266 each data point i.e. the morphological distance travelled by that branch. The $95 \%$ confidence

267 hyperellipsoid volume of each dietary regime was calculated using the functions in the $\mathrm{R}$

268 package Cluster (Maechler et al. 2008). The lineage density of each dietary regime was

269 calculated using the equation provided by Sidlauskas (2008).

\section{Character change histories}

The character list of Liebrecht et al. (2016) was divided into five categories based on the region to which the characters referred to: Skull, Palate, Mandible, Dentition and Postcranium.

274 The functions in the package Claddis automatically calculates the most likely combination of

275 character changes for each of the 100 time calibrate phylogenies alongside the analysis of rate 
276 variation. These character change histories were used to assess which region of the skeleton

277 underwent the greatest change within each dietary regime. Using the 10,000 stochastic maps of

278 the dietary character, the number of characters from each region changing within each dietary

279 regime was counted. These counts for each region were divided by the total number of character

280 changes occurring across the entire tree in that region to account for the fact that the characters

281 were not evenly distributed. The list of characters and the region to which they were assigned is

282 presented in supplementary data 4.

283

284 Results

285

286

287

Dietary evolution

Fitting of discrete models of character evolution to the dietary character indicates an equal rates model best fits the captorhinid phylogeny (Fig. 2). It should be noted that this support is not overwhelming; although the ER model is found to fit best in all 100 trees, in none does it receive an akaike weights score of above 0.8 . Using this model in ancestral state reconstructions

(Fig. 3) indicates a single transition to a herbivorous diet is most probable. Labidosaurus, judged to be an omnivore by Modesto et al. (2007) on the basis of the dental morphology, is found to most likely have evolved from a herbivorous ancestor, rather than Captorhinikos chozaensis and the Moradisaurinae representing convergent transitions to herbivory from an omnivorous ancestor. There is, however, considerable uncertainty; the probability of a herbivorous ancestor is not much more than $50 \%$. There is further uncertainty surrounding the ancestral diet of the

297 clade containing the three species of Captorhinus, Captorhinikos chozaensis, Labidosaurus and 298 the Moradisaurinae; while an omnivorous ancestor receives the highest likelihood, the 
299 probability is not much better than that of a carnivorous ancestor. This has implications for the

300 transition to herbivory; the transition from carnivory to herbivory may have passed through an

301 omnivorous phase, which was retained by the genus Captorhinus (Dodick \& Modesto 1995;

302 Kissel et al. 2002), or the genus Captorhinus may represent a transition to omnivory from

303 carnivory independent of the transition to herbivory.

304 For the three uncertain nodes, the ancestral state reconstruction using the RJ MCMC

305 method produced similar results. In fact this approach suggested less uncertainty surrounding the

306 ancestral states (supplementary figure 1). Thus the most probable evolutionary history inferred is

307 a single transition to herbivory via omnivory, with Labidosaurus representing a reversal to an

308 omnivorous diet from a herbivorous ancestor.

Analyses of Rate Heterogeneity

311 In the overwhelming majority of the 100 time calibrated trees, a significant rate increase

312 is identified along the branch leading to the Moradisaurinae (Fig. 4), the clade containing

313 exclusively herbivorous taxa. This result is robust to taxonomic jack-knifing: in $94 \%$ of the jack-

314 knife iterations a significant rate increase is identified along this branch. The position of other

315 significant increases in rate depends on the tree topology and the uncertainty in dating the taxa,

316 but in more than half of the trees the branch leading to the clade containing the Moradisaurinae,

317 Labidosaurus and Captorhinikos chozensis (the clade inferred to have a herbivorous ancestor)

318 are found to exhibit a rate increase, as is the lineage leading to the clade containing Labidosaurus

319 and Moradisaurinae in more than two thirds of the trees. Significant rate decreases are observed

320 in the lineages leading to Saurorictus and to Labidosaurus in the majority of the 100 trees. 
While the analyses did identify rate heterogeneity when comparing branches of the

322 phylogeny, when comparing rates of evolution in different time bins, very little was identified. In

323 all of the 100 time calibrate trees, a constant rate through time was found to have a higher

324 likelihood than a different rate in each time bin.

325

326

327

328

329

330

331

332

333

334

335

336

337

338

339

340

341

342

343

\section{Rates and Disparity in Different Dietary Regimes}

Of the 10,000 stochastic maps of dietary evolution in captorhinids, the herbivores have a higher mean rate of discrete character change than the omnivores in 9845 maps, and a higher rate than the carnivores in 9986 (Fig. 5a). When the mean rates of herbivores are compared to an equal number of branches drawn at random, the herbivores have a higher mean rate in 9484 of the stochastic map (Fig. 5b). This result is robust to taxonomic jack-knifing; in $98 \%$ of jack-knife iterations the mean rates of character change in herbivores are higher than the carnivores, and are higher than the omnivores in $97 \%$ of the iterations (supplementary figure 2). In all 10,000 stochastic maps, the mean morphological distance between the herbivorous taxa is greater than that of the omnivores and the carnivores, indicating a greater disparity (Fig. 6).

\section{Disparity Through Time}

When evolutionary change is assumed to be gradual (Fig. 7a), the carnivorous captorhinids show a gradual increase in morphological disparity up to a peak in the early Artinskian. Through the late Artinskian and Kungurian their disparity decreases, culminating in a fall to zero across the Kungurian/Roadian boundary, after which only one carnivorous captorhinid is included in the phylogeny (Saurorictus). The omnivorous captrohinids show a similarly gradual increase in disparity between the Asselian and Kungurian. Again, their 
344 disparity falls to zero across the Kungurian/Roadian boundary. The initial establishment of the

345 disparity of the herbivorous lineages is more rapid than that of the carnivores, having exceeded

346 the disparity of the carnivorous captorhinids by the early Kungurian. A disparity peak is reached

347 in the late Kungurian, higher than the peaks observed either in the carnivorous or omnivorous

348 curves. Herbivore disparity falls across the Kungurian/Roadian boundary, but recovers by the

349 Wuchiapingian.

350 If morphological change is assumed to be punctuated, with the morphological change

351 occurring at the speciation events (Fig. 7b), then in all three dietary classes peak morphological

352 disparity is reached soon after that regime's appearance and disparity remains fairly constant in

353 the bins following. As observed when using the gradualistic model, however, peak disparity of

354 the herbivores is higher than either the omnivores or the carnivores. Interestingly, the disparity of

355 herbivores already exceeds that of the other two dietary regimes by the Artinskian when using

356 the punctuated model. Moreover, the decrease in disparity observed in the herbivorous lineages

357 across the Kungurian/Roadian boundary is of a much lesser extent and disparity has recovered by 358 the Wordian.

\section{Lineage Density}

361 While there is considerable variation in the absolute lineage densities calculated within

362 each dietary regime (Fig. 8), the overwhelming majority of the 10,000 evolutionary histories

363 examined show the same relative pattern. In 9926 of these, the lowest lineage density is found in

364 the herbivores, while the highest lineage density is observed in the omnivores. In only 58 of the

36510,000 stochastic maps do the carnivores have a lower lineage density than the herbivores. 
367

368

369

370

371

372

373

374

375

376

377

378

379

380

381

382

383

384

385

386

387

388

389

\section{Character Change Histories}

The majority of character changes in the carnivorous lineages occurred in the skull and postcranium (Fig. 9a). In most the 10,000 stochastic maps the feeding apparatus (teeth and mandible) remain more conservative, with a lower proportion of character changes occurring in these regions. This changes with the transition to herbivory: the majority of the characters changing in herbivorous captorhinids are dental characters and, in many of the stochastic maps (but not all), mandibular characters (Fig. 9c). The postcranium and skull, the most plastic regions in the carnivorous captorhinids, show lower proportions of character change in this new dietary regime. There is little difference in the proportions of characters changing in each region in the omnivorous captorhinids (Fig. 8b).

\section{Discussion}

The link between a supposed "key innovation" and an adaptive radiation must always, to a certain extent, be circumstantial; one may identify the branch in a phylogeny along which the evolutionary novelty likely appeared, and one may identify the location of shifts in rates of evolution and diversification, but conclusively proving a causal relationship between the two is extremely difficult. Nevertheless, the evidence supporting an adaptive radiation of captorhinids coinciding with the origin of herbivory in this clade is compelling. It is only along herbivorous branches that significant increases in rates of morphological evolution are identified in the majority of the 100 time calibrated trees, and in the overwhelming majority stochastic maps the mean rate evolution in herbivorous lineages is higher not only than in the other dietary categories but crucially is also higher than in randomly selected clusters of taxa with an equal sample size 
390 in more than $94 \%$ of the stochastic maps. Further support for higher rates of evolution among

391 herbivorous captorhinids than in other dietary regimes can be found in the lineage leading to

392 Labidosaurus; a reversal from a herbivorous ancestor to an omnivorous taxon usually coincides

393 with a significant decrease in rates of evolution. The herbivorous captorhinids also occupy a

394 wider range of morphologies than the other dietary categories, indicating that the increased rate

395 of evolution was an exploration of new morphologies, not simply re-entering established regions

396 of morphospace. This inference is supported by them consistently showing a lower lineage

397 density than either of the other two dietary regimes. When one examines the phylomorphospace

398 (Fig. 10), one may observe that the carnivorous lineages are concentrated in a small region: low

399 values of PC1 and PC2. The Omnivores are found at higher values of PC2. The herbivores,

400 however, explore a great range of values along PC1, and represent the extreme values of PC2.

401 While carnivorous and omnivorous captorhinids both show a gradual increase in disparity

402 up to a peak in the Artinskian and Kungurian respectively, the herbivorous captorhinids show a

403 much more rapid increase in morphological diversity. Herbivorous taxa don't appear in the fossil

404 record until the Kungurian (although calibrating the phylogeny using the Hedman approach

405 indicates an earlier origin), yet by the late Kungurian they already show a greater morphological

406 diversity than either the carnivores or omnivores show at any point in their evolutionary history.

407 Although the disparity of herbivores falls across the Kungurian/Roadian boundary, a trough

408 possibly related to the mass extinction event known as Olson's Extinction (Sahney \& Benton

409 2008; Brocklehurst et al. 2015) the morphological diversity recovers during the Guadalupian and

410 Lopingian, reaching an even higher peak of disparity by the Wuchiapingian. Even though the

411 species richness of captorhinids is substantially decreased by Olson's extinction, the herbivorous

412 lineages continue to show increased morphological innovation. It is possible that the herbivorous 
413 captorhinids were more resilient to extinction than others: they make up the majority of the post-

414 extinction diversity, and Middle/Late Permian carnivorous species exhibit low abundances (Jalil 415 and Dutuit 1996; Golubev 2000; Smith \& Modesto 2001). Moreover, the late Permian carnivore

416 included in this analysis, Saurorictus, appears to experience a significant decrease in rates of

417 evolution contrasting with its herbivorous relatives (Figure 4). This pattern has been previously

418 observed in Paleozoic and Mesozoic amniotes: the higher species richness of specialist

419 herbivores appears to be driven not by increased origination rates but by higher extinction rates

420 in their close relatives (Brocklehurst et al. 2015).

421 One interesting point to note is that, although herbivores overall show increased rates,

422 disparity and exploration of novel morphotypes than carnivores or omnivores, the significant rate 423 increases appear to be concentrated along the backbone of the herbivorous lineage; in very few 424 of the time calibrated trees are rate increases observed along terminal herbivorous lineages (Fig. 425 4). This may also be seen in plots of the phylomorphospace (Fig. 10); the greatest changes in 426 morphology occurred along the lineage leading to Moradisaurinae and the lineage leading to the 427 clade containing Rothianiscus and the specimen MBCN 15739 (the captorhinid from Mallorca).

428 The only herbivorous terminal branch along which a similar quantity of morphological change is 429 observed is Rothianiscus, and this taxon is returning to an already-explored region of 430 morphospace. From this, one may perhaps infer a slow-down of the diversification rate following 431 the initial rate increase during the first appearance of herbivory, i.e. an early-burst model.

432 While the coincidence of the rate and disparity increase with the "key innovation" does

433 not necessarily indicate cause and effect, the nature of the morphological changes provides much

434 stronger evidence. It is not only that the rate of character changes increases coinciding with the

435 shift in diet, but it is that the character changes within the herbivores are those referring to the 
436 mandible and dentition; that is, the characters related to the feeding apparatus. In the carnivorous

437 captorhinids, the majority of the character changes occur in the skull and the postcranium, while

438 the dentition remains extremely conservative. It is this observation that moves the inference of an

439 adaptive radiation driven by a key innovation beyond one based on the circumstantial evidence

440 discussed above. The evolution of a herbivorous diet occurs alongside not only an increase in the

441 rate of character changes, but a shift in the pattern of the changes. The changes occurring during

442 the adaptive radiation are directly related to the innovation supposedly driving it, a stronger

443 indicator of a causal relationship.

444 Prior to the evolution of herbivory in captorhinids the overwhelming majority of

445 vertebrate herbivores were large (Reisz \& Fröbisch 2014; Reisz \& Sues 2000). Edaphosaurids

446 were the most diverse and abundant high-fibre herbivores throughout much of the Pennsylvanian

447 and the Early Permian (Pearson et al. 2013; Reisz \& Sues 1998), although they go into decline

448 before the end of the Cisuralian. In the latest Cisuralian Hennessey Formation of Oklahoma they

449 are represented solely by some neural spine fragments (Daly 1973), whilst the only supposed

450 edaphosaurid from the contemporary Clear Fork Group of Texas was recently re-described as an

451 indeterminate moradisaurine captorhinid (Modesto et al. 2016).

452 It has been suggested that edaphosaurids and mordaisaurine captorhinids were occupying

453 similar ecological niches (Modesto et al. 2014); they both convergently evolved similar

454 strategies to deal with plant material (upper and lower tooth-plates and a propalineal motion of

455 the lower jaw). The possibility of competition has been mooted (Modesto et al. 2014), with the

456 moradisaurines replacing the edaphosaurids. However, Modesto et al. (2016) rejected this due to

457 the limited stratigraphic overlap between the two. Moreover, while edaphosaurids show selection

458 towards larger body size (Reisz \& Fröbisch 2014; Brocklehurst \& Brink 2017), the herbivorous 
459 captorhinids show a greater tendency towards decreases in body size than increases

460 (Brocklehurst 2016), possibly indicating niche partitioning instead of competition. During the

461 latest Cisuralian genera such as Captorhinikos and Labidosaurikos become the most abundant

462 small herbivores (Brocklehurst et al. 2017), rather than replacing edaphosaurids as large

463 herbivores.

464 Instead of viewing them as supplanting edaphosaurids, Modesto et al. (2016) suggested

465 that the changing climate of the time was responsible for the radiation of the moradisaurine

466 captorhinids. It is true that the radiation of the Moradisaurinae does coincide with a shift towards

467 a warmer, drier, more seasonal climate, and the captorhinids continue to thrive in the arid

468 equatorial regions for the rest of the Permian (Dutuit 1976; Ricqlès et al. 1982; O'Keefe et al.

469 2005, Brocklehurst et al. 2017), in contrast to their rarity in temporal regions. However, the

470 analysis of rates through time casts doubt on this explanation. An extrinsic driver of increased

471 morphological diversity, such as climate changes, should produce a rate shift during a specific

472 interval of time rather than in a specific clade. The data presented here, on the other hand,

473 suggests no significant increase in rate during the Kungurian. In fact, in all the time calibrated

474 phylogenies a constant rate through time best fits the observed data. The shifts in rate occur

475 along specific branches, not during a specific interval, and therefore must be associated with an

476 intrinsic cause.

477 It is therefore considered more likely that the shift in diet is the cause for the adaptive

478 radiation; specifically, the shift into the "small herbivore" niche that did not require competition

479 with edaphosaurids, caseids and diadectids. Although bolosaurid parareptiles did occupy this

480 niche in some areas during the early and middle Permian, they are comparatively rare and exhibit

481 low species richness (Reisz \& Fröbisch 2014). The radiation observed in captorhinids represents 
482 an expansion into an extremely under-filled region of ecospace, which they could occupy more

483 efficiently than bolosaurids. It is possible that the increased dental and mandibular innovation

484 allowed the captorhinids their greater success. Herbivorous captorhinids possess multiple tooth

485 rows (in some taxa as many as eleven) and the ability to move the jaw propalineally (Heaton

486 1979; Doddick \& Modesto 1995; Modesto et al. 2007, 2014), creating an effective surface for

487 grinding and shredding plant matter. Other dental and mandibular innovations appearing within

488 the Moradisaurinae include a saddle-shaped occlusal surface of the teeth and a more robust

489 ramus of the jaw.

490

491 Conclusions

492 - A single transition to herbivory in Captorhinidae is most found to be most probably,

493 although whether from a carnivorous or omnivorous ancestor is unclear. Labidosaurus

494 appears to represent a reversal to an omnivorous diet from a herbivorous ancestor.

495 - Significant increases in rates of discrete character change are observed coinciding with

496 the origin of herbivory. The herbivorous lineages are found to have higher rates of

497 evolution than their carnivorous and omnivorous relatives.

498 - The herbivorous captorhinids were more morphologically diverse than their carnivorous

499 and omnivorous relatives, and reached their peak disparity more rapidly.

500 - The shift to higher rates of discrete character change is accompanied by a shift towards

501 increased evolution of the mandible and dentition, supporting a causal link between the

502 origin of a herbivorous diet and the radiation observed in captorhinids during the

$503 \quad$ Kungurian. 


\section{Acknowledgements}

I would like to thank Graeme Lloyd for helpful discussion and assistance with the $\mathrm{R}$ package Claddis. Roger Close offered comments on an early draft of the manuscript. Martin Ezcurra, Manabu Sakamoto and an anonymous reviewer made many helpful suggestions which

510 greatly improved the manuscript.

511

512

\section{References}

514 Benson RBJ, and Choiniere JN. 2013. Rates of dinosaur limb evolution provide evidence for 515 exceptional radiation in Mesozoic birds. Proceedings of the Royal Society B 280:20131780.

517 Bollback JP. 2006. SIMMAP: stochastic character mapping of discrete traits on phylogenies. BMC bioinformatics 7:88.

519 Brocklehurst N. 2016. Rates and modes of body size evolution in early carnivores and herbivores: a case study from Captorhinidae. PeerJ 4:e1555.

521 Brocklehurst N, and Brink K. 2016. Selection towards larger body size in both herbivorous and carnivorous synapsids during the Carboniferous. Facets 2: 68-84.

523 Brocklehurst N, Ruta M, Müller J, and Fröbisch J. 2015. Elevated extinction rates as a trigger for diversification rate shifts: early amniotes as a case study. Scientific Reports 5:17104.

525 Brocklehurst N, Day MO, Rubidge BS, Fröbisch J. 2017. Olson's extinction and the latitudinal biodiversity gradient of tetrapods in the Permian. Proceedings of the Royal Society B: In Press 
528 Brusatte SL, Lloyd GT, Wang SC, and Norell MA. 2014. Gradual assembly of avian body plan

529 culminated in rapid rates of evolution across the dinosaur-brid transition. Current Biology $530 \quad 24: 2386-2392$.

531 Brusatte SL, Montanari S, Hong-yu Y, and Norell MA. 2011. Phylogenetic corrections for 532 morphological disparity analysis: new methodology and case studies. Paleobiology 37:122.

534 Close RA, Friedman M, Lloyd GT, and Benson RBJ. 2015. Evidence for a mid-Jurassic adaptive radiation in mammals. Current Biology 25:2137-2142.

536 Cook JA, and Lessa EP. 1998. Are rates of diversifiaction in subterranean South American tucotucos (genus Ctenomys, Rodentia: Octodontidae) unusually high? Evolution 52:15211527.

Daly E. 1973. A Lower Permian vertebrate fauna from southern Oklahoma. Journal of Paleontology 47:562-589.

541 Dodick JT, and Modesto S. 1995. The cranial anatomz of the captorhinid reptile Labidosaurikos meachami from the Lower Permian of Oklahoma. Palaeontology 38:687.

543 Donoghue MJ. 2005. Key innovations, convergence, and success: macroevolutionary lessons $544 \quad$ from plant phylogeny. Paleobiology 31:77-93.

545 Forest F, Chase MW, Persoon C, Crane PR, and Hawkins JA. 2007. The role of biotic and 546 abiotic factors in evolution of ant dispersal in the milkwort family (Polygalaceae). $547 \quad$ Evolution 61:1675-1694.

548 Givnish TJ. 2010. Ecology of plant speciation. Taxon 59:1326-1366. 
549 Givnish TJ. 2015. Adaptive radiation versus 'radiation' and 'explosive diversification': why 550 conceptual distinctions are fundamental to understanding evolution. New Phytologist $551 \quad 207: 297-303$.

552 Golubev, V.K., 2000. The faunal assemblages of Permian terrestrial vertebrates from eastern 553 Europe. Paleontological Journal 34:211-224.

554 Harmon LJ, Weir JT, Brock CD, Glor RE, and Challenger W. 2008. GEIGER: investigating 555 evolutionary radiations. Bioinformatics 24:129-131.

556 Harmon LJ, Losos JB, Davies TJ, Gillespie RG, Gittleman JL, Jennings BW, Kozak KH, 557 McPeek MA, Moreno-Roark F, Near TJ, and Purvis A. 2010. Early bursts of body size and shape evolution are rare in comparative data. Evolution 64:2385-2396.

559

560

561

562

563

564

565

566

567

568

569

Heaton MJ. 1979. Cranial anatomy of primitive captorhinid reptiles from the Late Pennsylvanian and Early Permian, Oklahoma and Texas. Bulletin of the Oklahoma Geological Survey 127:1-84.

Hedman MM. 2010. Constraints on clade ages from fossil outgroups. Paleobiology 36:16-31.

Hughes M, Gerber S, and Wills MA. 2013. Clades reach highest morphological disparity early in their evolution. Proceedings of the National Academy of Sciences 110: 13875-13879.

Jalil NE, and Dutuit JM. 1996. Permian captorhinid reptiles from the Argana Formation, Morocco. Palaeontology 39:907-918.Kazancioğlu E, Near TJ, Hanel R, and Wainwright PC. 2009. Influence of sexual selection and feeding functional morphology on diversification rate of parrotfish (Scaridae). Proceedings of the Royal Society B 276:3439-3446. 
570 Kissel RA, Dilkes DW, and Reisz RR. 2002. Captorhinus magnus, a new captorhinid (Amniota:

571 Eureptilia) from the Lower Permian of Oklahoma, with new evidence on the homology of

572 the astragulus. Canadian Journal of Earth Sciences 39:1363-1372.

573 Kozak KH, Larson AA, Bonett RM, and Harmon LJ. 2005. Phylogenetic analysis of

574 ecomorphological divergence, comminity structure, and diversification rates in dusky

575 salamanders (Plethodontidae: Desmognathus). Evolution 59:2000-2016.

576 Labandeira CC. 1998. Early history of arthropod and vascular plant associations. Annual Review

$577 \quad$ of Earth and Planetary Sciences 26:329-377.

578 Labandeira CC. 2007. The origin of herbivory on land: initial patterns of plant tissue

579 consumption by arthropods. Insect Science 14:259-275.

580 Leibrecht T, Fortuny J, Galobart A, Müller J, and Sander M. 2016. A large, multiple-tooth-rowed

581 captorhinid reptile (Amniota: Eureptilia) from the upper Permian of Mallorca (Balearic

582 Islands, western Mediterranean). Journal of Vertebrate Paleontology: In Press.

583 Lloyd GT. 2016. Estimating morphological diversity and tempo with discrete character-taxon

584 matrices: implementation, challenges, progress and future directions. Biological Journal

$585 \quad$ of the Linnean Society 118:131-115.

586 Lloyd GT, Bapst DW, Friedman M, and Davis KE. 2016. Probabilistic divergence time

587 estimation without branch lengths: dating the origins of dinosaurs, avian flight and crown

$588 \quad$ birds. Biology Letters 12:20160609.

589 Lloyd GT, Wang SC, and Brusatte SL. 2012. Identifying hetergeneity in rates of morphological

590 evolution: discrete character change in the evolution of lungfish (Sarcopterygii; Dipnoi).

$591 \quad$ Evolution 66:330-348. 
592 McLeish MJ, Chapman TW, and Schwarz MP. 2007. Host-driven diversification of gall-

593 inducing Accacia thrips and the aridification of Australia. BMC Biology

$594 \quad$ 5:doi:10.1186/1741-7007-1185-1183.

595 Modesto S, and Smith RM. 2001. A new Late Permian captorhinid reptile: a first record from the 596 South African Karoo. Journal of Vertebrate Paleontology 21:405-409.

597 Modesto S, Flear VJ, Dilney MM, and Reisz RR. 2016. A large moradisaurine tooth plate from 598 the Lower Permian of Texas and its biostratigraphic implications. Journal of Vertebrate $599 \quad$ Paleontology:e1221832.

600 Modesto S, Lamb AJ, and Reisz RR. 2014. The captorhinid reptile Captorhinikos valensis from 601 the lower Permian Vale Formation of Texas, and the evolution of herbivory in eureptiles. 602 Journal of Vertebrate Paleontology 34:291-302.

603 Modesto S, Scott D, Berman DS, Müller J, and Reisz RR. 2007. The skull and palaeoecological 604 significance of Labidosaurus hamatus, a captorhinid reptile from the Lower Permian of 605 Texas. Zoological Journal of the Linnean Society 149:237-262.

Müller J, and Reisz RR. 2005a. An early captorhinid reptile (Amniota, Eureptilia) from the Upper Carboniferous of Hamilton, Kansas. Journal of Vertebrate Paleontology 25:561608 568.

Müller J, and Reisz RR. 2005b. The phylogeny of early eureptiles: comparing parsimony and Bayesian approaches in the investigation of a basal fossil clade. Systematic Biology 55:503-511.

612 Neige P, Dera G, and Dommergues JL. 2013. Adaptive radiation in the fossil record: a case study 613 among Jurassic ammonoids. Palaeontology 56:1247-1261. 
614 O'Keefe FR, Sidor CA, Larsson HC, Maga A, and Ide O. 2005. The vertebrate fauna of the

615 Upper Permian of Niger-III, morphology and ontogeny of the hindlimb of Moradisaurus

616 grandis (Reptilia, Captorhinidae). Journal of Vertebrate Paleontology 25:309-319.

617 Olson EC. 1966. Community evolution and the origin of mammals. Ecology 47:291-302.

618 Paradis E, Claude J, and Strimmer K. 2004. APE: analyses of phylogenetics and evolution in R 619 language. Bioinformatics 20:289-290.

620 Parfrey LW, Lahr DJ, Knoll AH, and Katz LA. 2011. Estimating the timing of early eukaryotic 621 diversification with multigene molecular clocks. Proceedings of the National Academy of 622 Sciences 108:13624-13629.

623 Pearson MR, Benson RBJ, Upchurch P, Fröbisch J, and Kammerer CF. 2013. Reconstructing the 624 diversity of early terrestrial herbivorous tetrapods. Palaeogeography, Palaeoclimatology, $625 \quad$ Palaeoecology 372:42-49.

626 Pol D, and Norell MA. 2006. Uncertainty in the age of fossils and the stratigraphic fit to 627 phylogenies. Systematic Biology 55:512-521.

628 R Core Team. 2014. R: A language and environment for statistical computing. R Foundation for 629 Statistical Computing, Vienna, Austria

630 Reisz RR. 1972. Pelycosaurian reptiles from the Middle Pennsylvanian of North America.

631 Bulletin of the Museum of Comparitive Zoology 144:27-60.

632 Reisz RR, and Fröbisch J. 2014. The oldest caseid synapsid from the Late Pennsylvanian of 633 Kansas and the evolution of herbivory in terrestrial vertebrates. PlosOne 9:e94518.

634 Reisz RR, and Sues H-D. 2000. Herbivory in late Paleozoic and Triassic terrestrial vertebrates.

635 In: Sues H-D, ed. Evolution of Herbivory in Terrestrial Vertebrates: Perspectives from 636 the Fossil Record. Cambridge: Cambridge University Press. 
637 Ricqlès AD, and Taquet P. 1982. La faune de vertébrés du Permien supérieur du Niger. I. Le 638 Captorhinomorphe Moradisaurus grandis (Reptilia, Cotylosauria)—Le crâne. Annales de $639 \quad$ Paléontologie 68:33-106.

640 Ruber L, Van Tassell JL, and Zardoya R. 2003. Rapid speciation and ecological divergence in 641 the American seven-spines gobies (Gobiidae, Gobiosomatini) inferred from a molecular 642 phylogeny. Evolution 57:1584-1598.

643 Ruta M, and Coates MI. 2007. Dates, nodes and character conflict: addressing the lissamphibian 644 origin problem. Journal of Systematic Palaeontology 5:69-122.

645 Sahney S, and Benton MJ. 2008. Recovery from the most profound mass extinction of all time. $646 \quad$ Proceedings of the Royal Society B 275.

647 Scott AC, and Taylor TN. 1983. Plant/animal interactions during the Upper Carboniferous. The $648 \quad$ Botanical Review 49: 259-307.

649 Shear WA. 2000. The early development of terrestrial ecosystems. In: Gee, H, ed. Shaking the 650 tree: readings from nature in the history of life. Chicago: University of Chicago Press, pp.169-179.

Sidlauskas, B. 2008. Continuous and arrested morphological diversification in sister clades of 653 characiform fishes: a phylomorphospace approach. Evolution 62:3135-3156

Simpson GG. 1953. The Major Features of Evolution. New York: Columbia University Press.

655 Simões M, Breitkreuz L, Alvarado M, Baca S, Cooper JC, Heins L, Herzog K, and Lieberman 656 BS. 2016. The evolving theory of evolutionary radiations. Trends in Ecology \& Evolution 31:27-34.

658 Slater, G. 2013. Phylogenetic evidence for a shift in the mode of mammalian bodysize evolution 659 at the Cretaceous-Palaeogene boundary. Methods in Ecology and Evolution 4:734-744 
660 Sues H-D, and Reisz RR. 1998. Origins and early evolution of herbivory in tetrapods. Trends in $661 \quad$ Ecology and Evolution 13:141-145.

662 Vences M, Andreone F, F. G, Kosuch J, Meyer A, Schaefe HC, and Veith M. 2002. Exploring 663 the potential of life-history key innovation: brook breeding in the radiation of the 664 Malagasy treefrog genus Boophis. Molecular Ecology 11:1453-1463.

665

666

667 Figure Captions

668 Figure 1

669 Title: An illustration of the methods used to calculate disparity in this study

670 Legend: (A) A hypothetical phylogeny illustrating as solid dots the data points that would be 671 included under the method of Brusatte et al. (2010): the tip taxa A, B and C, and the

672

673

674

675

676

677 Nodes 1 and 2; (B) The phylogeny plotted against a hypothetical trait, illustrating how the morphology of the lineage leading to Taxon $\mathrm{C}$ in time bin 1 and the morphology of the lineage leading to taxon $\mathrm{A}$ in time bin 2 may be inferred assuming a gradual model of evolution with no rate variation along a branch; (C) An illustration of how the same morphologies are inferred assuming a punctuated model of evolution, where the morphological change occurs at the speciation event

678

679 Figure 2

680 Title: The fit of models of diet evolution to the phylogeny of Captorhinidae.

681 Legend: Boxplots illustrating the distribution of 100 Akaike weights values calculated for each 682 of the models of the evolution of diet as a discrete character, fit to the 100 time calibrated 
683

684

685

686 Figure 3

687

688

689

690

691

692

693

694

695

696

697

698

699

700

701

702

703

704

705

Figure 4 phylogenies of captorhinids. ER = Equal Rates; $\mathrm{SYM}=$ Symmetrical; $\mathrm{ARD}=$ All Rates

Different

Title: The phylogeny of Captorhinidae, illustrating the evolution of diet.

Legend: Two of the 100 time calibrate phylogenies used in the analysis. The thick branches represent the observed ranges of each taxon. The colours of the tip labels represent the diet inferred for that taxon: Red $=$ Carnivore, Blue $=$ Omnivore, Green $=$ Herbivore The pie charts at each node represent the probability of each dietary regime inferred for that node, deduced by maximum likelihood ancestral state reconstruction. (A) MPT 1: Opisthodontosaurus is the sister to the clade containing Rhiodenticulatus and all captrorhinids more derived. (B) MPT 2: Opisthodontosaurus is the sister to Concordia.

Title: The phylogeny of Captorhinidae, illustrating the location of significant changes in rates of evolution.

Legend: Two of the 100 time calibrate phylogenies used in the analysis. The thick branches represent the observed ranges of each taxon. The colours of the tip labels represent the diet inferred for that taxon: Red $=$ Carnivore, Blue $=$ Omnivore, Green $=$ Herbivore The pie charts on each branch represent the proportion of the 100 time calibrated phylogenies which show significantly high or low rates of evolution along that branch: $\operatorname{Red}=$ significantly high rates, Blue = significantly low rates, White $=$ no significant rate variation. (A) MPT 1: Opisthodontosaurus is the sister to the clade containing 

the sister to Concordia.

708

709 Figure 5

710 Title: A comparison of the mean rates of evolution within each dietary regime.

711 Legend: (A) Histogram illustrating the mean rate of discrete character evolution calculate for 712 each dietary regime in each of the 10,000 stochastic maps of dietary evolution; (B) Histogram illustrating the mean rate of discrete character evolution calculate for the herbivorous lineages compared to a random selection of branches with an equal sample size in each of the 10,000 stochastic maps of dietary evolution.

717 Figure 6

718 Title: A comparison of the morphological distances between taxa within each dietary regime.

719 Legend: Histogram illustrating the mean MORD distance between each taxon in each each 720 dietary regime in each of the 10,000 stochastic maps of dietary evolution.

721

722 Figure 7

723 Title: A comparison of disparity through time of the captorhinids in each dietary regime

724 Legend: The disparity (sum of variances) calculated for all taxa within each dietary regime in each time bin. Values shown in the graph are the means of the values calculated in 10,000 stochastic maps of dietary evolution. The dashed line represents the mass extinction event dubbed Olson's Extinction. (A) Morphology along each branch calculated assuming a 
728

729

730

$731 \quad$ Figure 8

732

733

734

735

736

737

738

739

740

741

742

743

744

745

746

747

748

749

750

Figure 9

Figure 10 gradualist model of evolution; (B) Morphology along each branch calculated assuming a punctuated model of evolution.

Title: Lineage densities of captorhinids in each dietary regime

Legend: Boxplots indicating the distribution lineage densities of the captorhinids in each dietary regime, calculated in each of the 10,000 stochastic maps of dietary evolution.

Title: The proportion of characters within each skeletal region changing within each dietary regime

Legend: Boxplots illustrating the distribution of the proportions of character changes in each skeletal region occur in each dietary regime, calculated in each of the 10,000 stochastic maps of dietary evolution. (A) Carnivores; (B) Omnivores; (C) Herbivores.

Title: Phylomorphospace of captorhinids.

Legend: The phylogeny of captorhinids plotted over principal coordinates 1 and 2. Colours of lineages represent the die found to have the highest probability by the likelihood ancestral state reconstruction. Taxon labels - 1: Thuringothyris; 2: Concordia; 3 :

Opisthodontosaurus; 4: Rhiodenticulatus; 5: Reiszorhinus; 6: Romeria prima; 7: Romeria texana; 8: Protocaptorhinus; 9: Saurorictus; 10: Captorhinus laticeps; 11: Captorhinus aguti; 12: Captorhinus magnus; 13: Captorhinikos chozensis; 14: Labidosaurus; 15 : 


\section{Figure 1}

\section{An illustration of the methods used to calculate disparity in this study}

(A) A hypothetical phylogeny illustrating as solid dots the data points that would be included under the method of Brusatte et al. (2010): the tip taxa A, B and C, and the Nodes 1 and 2; (B) The phylogeny plotted against a hypothetical trait, illustrating how the morphology of the lineage leading to Taxon $C$ in time bin 1 and the morphology of the lineage leading to taxon A in time bin 2 may be inferred assuming a gradual model of evolution with no rate variation along a branch; (C) An illustration of how the same morphologies are inferred assuming a punctuated model of evolution, where the morphological change occurs at the speciation event. 
A.

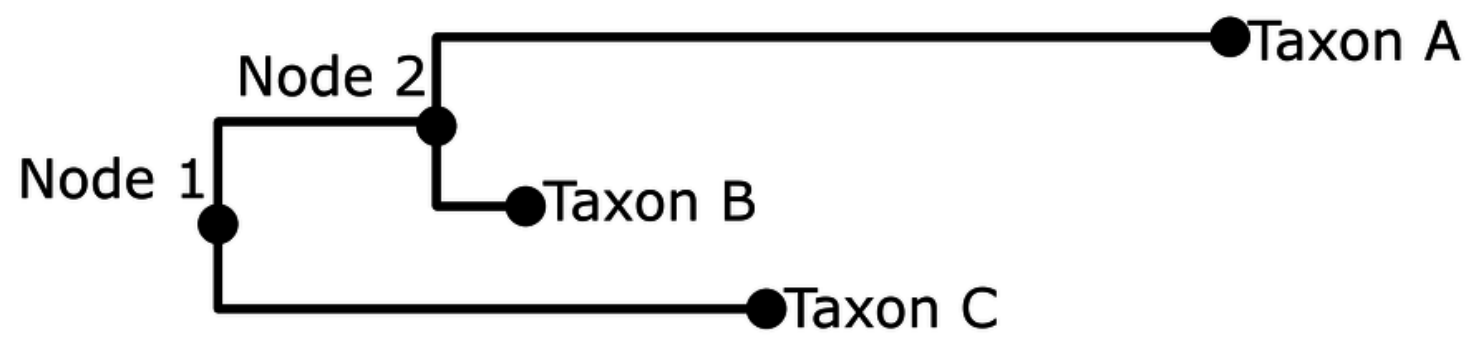

B.

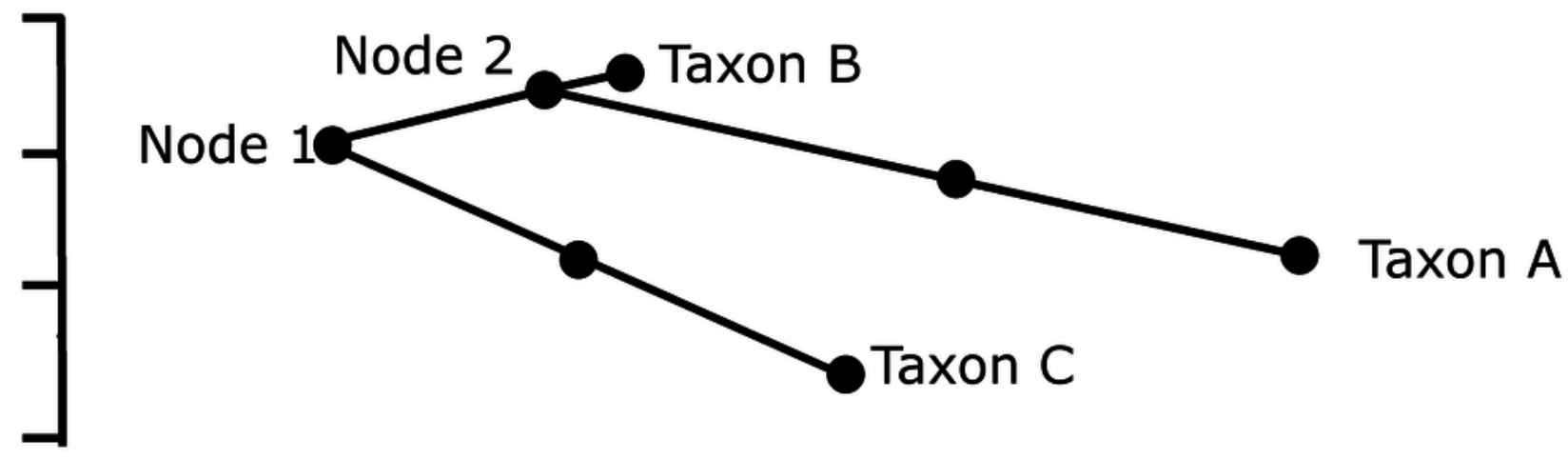

C.

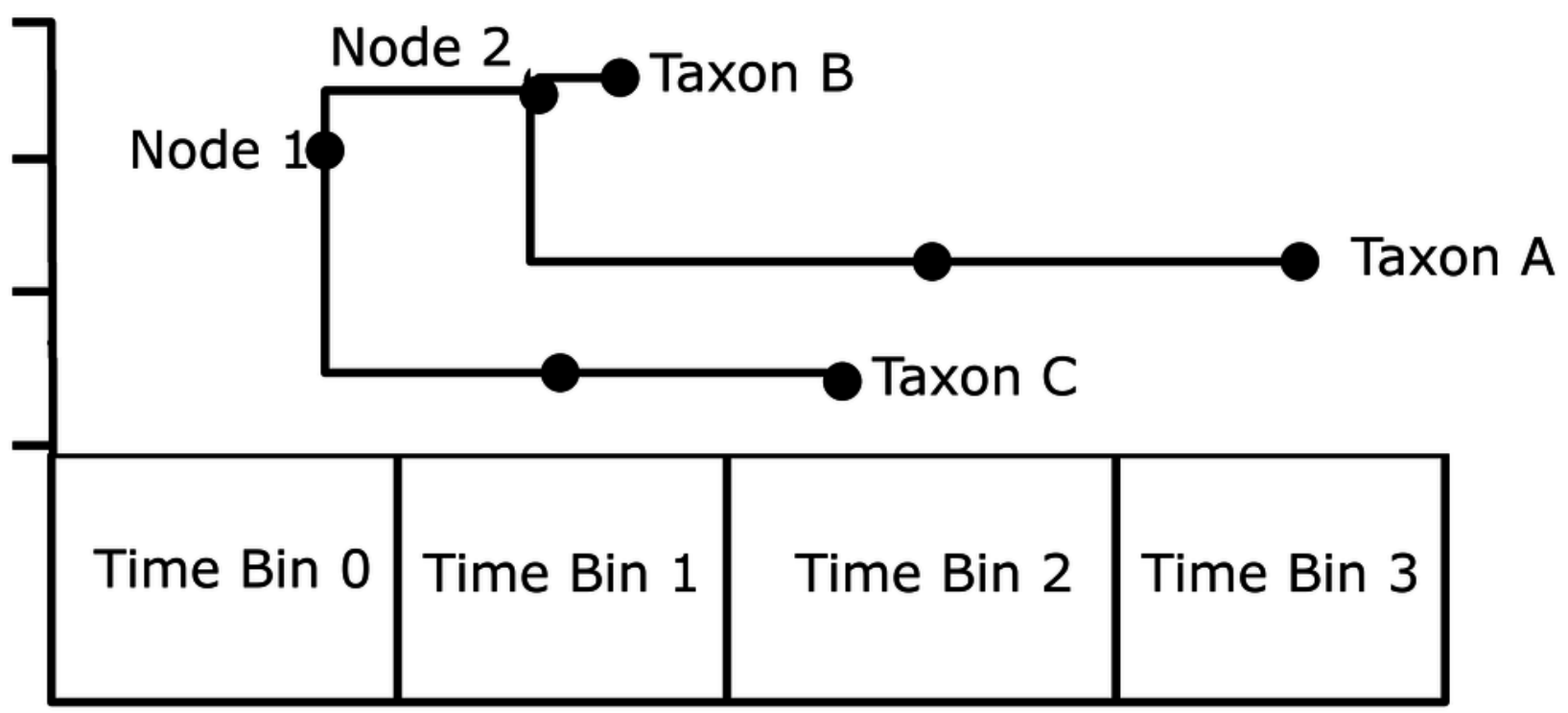


Figure 2

The fit of models of diet evolution to the phylogeny of Captorhinidae

Boxplots illustrating the distribution of 100 Akaike weights values calculated for each of the models of the evolution of diet as a discrete character, fit to the 100 time calibrated phylogenies of captorhinids. ER = Equal Rates; SYM = Symmetrical; $A R D=$ All Rates Different.

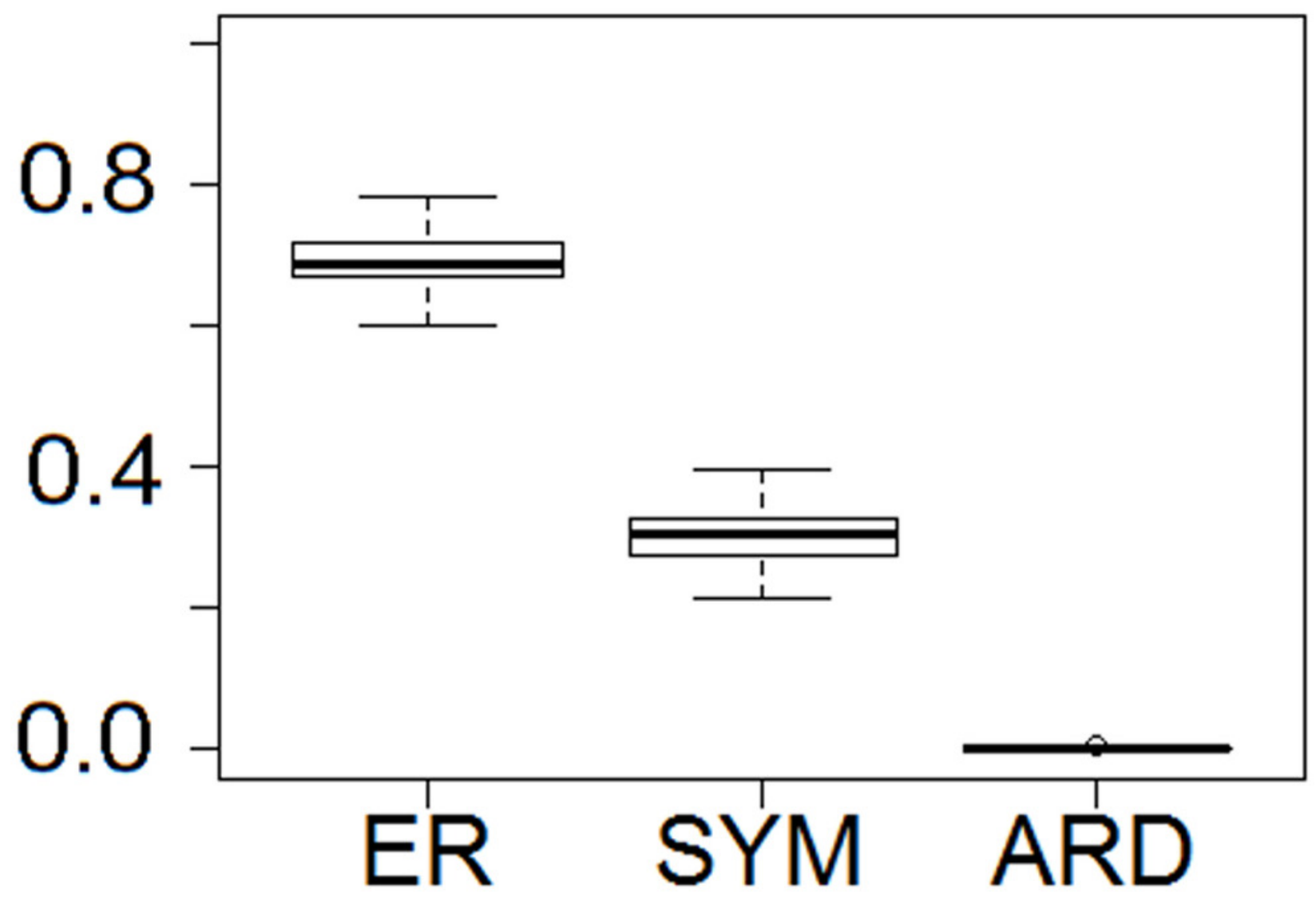




\section{Figure 3}

The phylogeny of Captorhinidae, illustrating the evolution of diet.

Two of the 100 time calibrate phylogenies used in the analysis. The thick branches represent the observed ranges of each taxon. The colours of the tip labels represent the diet inferred for that taxon: Red $=$ Carnivore, Blue $=$ Omnivore, Green $=$ Herbivore. The pie charts at each node represent the probability of each dietary regime inferred for that node, deduced by maximum likelihood ancestral state reconstruction. (A) MPT 1: Opisthodontosaurus is the sister to the clade containing Rhiodenticulatus and all captrorhinids more derived. (B) MPT 2: Opisthodontosaurus is the sister to Concordia. 


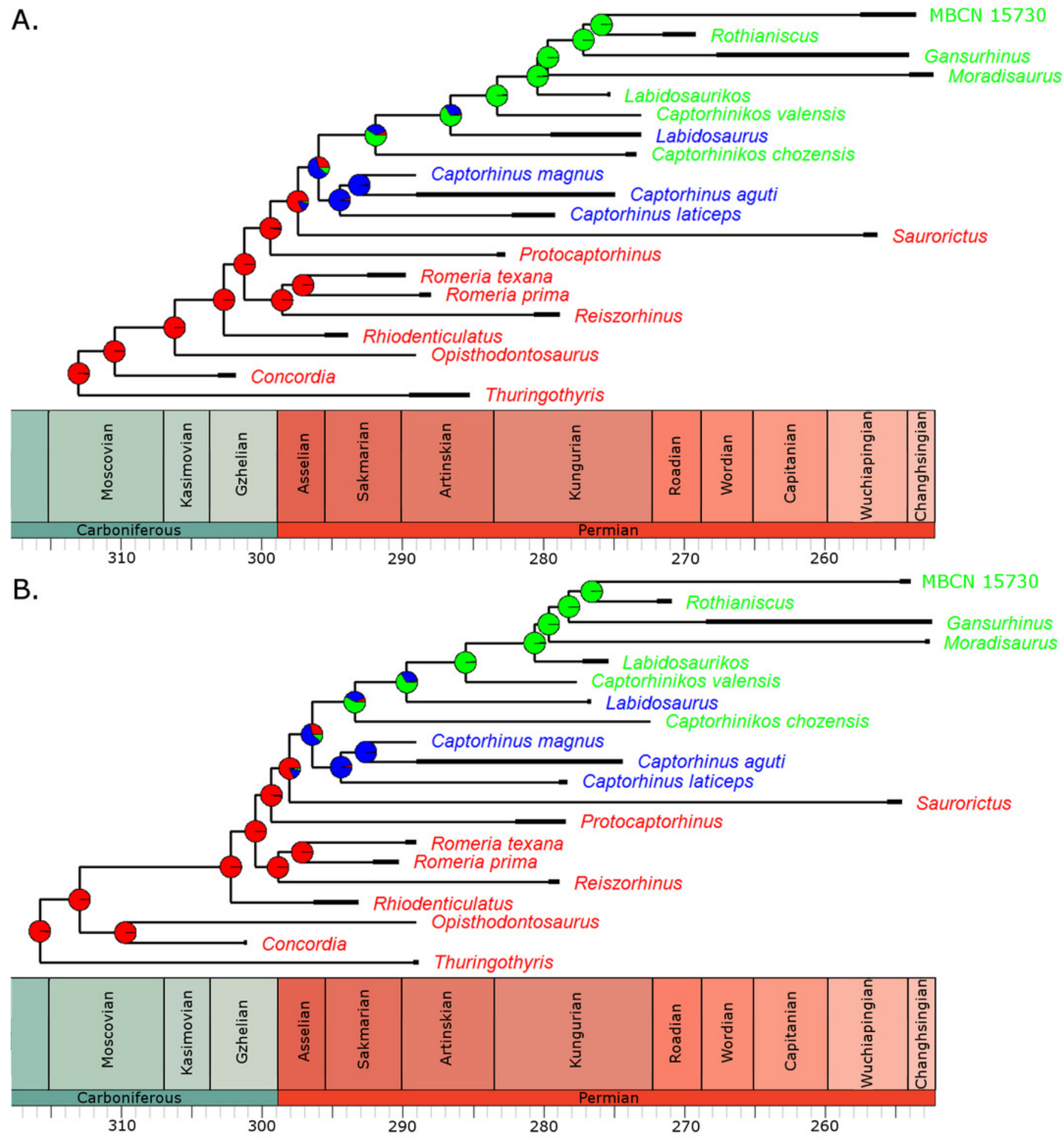




\section{Figure 4}

The phylogeny of Captorhinidae, illustrating the location of significant changes in rates of evolution.

Two of the 100 time calibrate phylogenies used in the analysis. The thick branches represent the observed ranges of each taxon. The colours of the tip labels represent the diet inferred for that taxon: Red = Carnivore, Blue $=$ Omnivore, Green $=$ Herbivore. The pie charts on each branch represent the proportion of the 100 time calibrated phylogenies which show significantly high or low rates of evolution along that branch: Red $=$ significantly high rates, Blue $=$ significantly low rates, White $=$ no significant rate variation. (A) MPT 1: Opisthodontosaurus is the sister to the clade containing Rhiodenticulatus and all captrorhinids more derived. (B) MPT 2: Opisthodontosaurus is the sister to Concordia. 


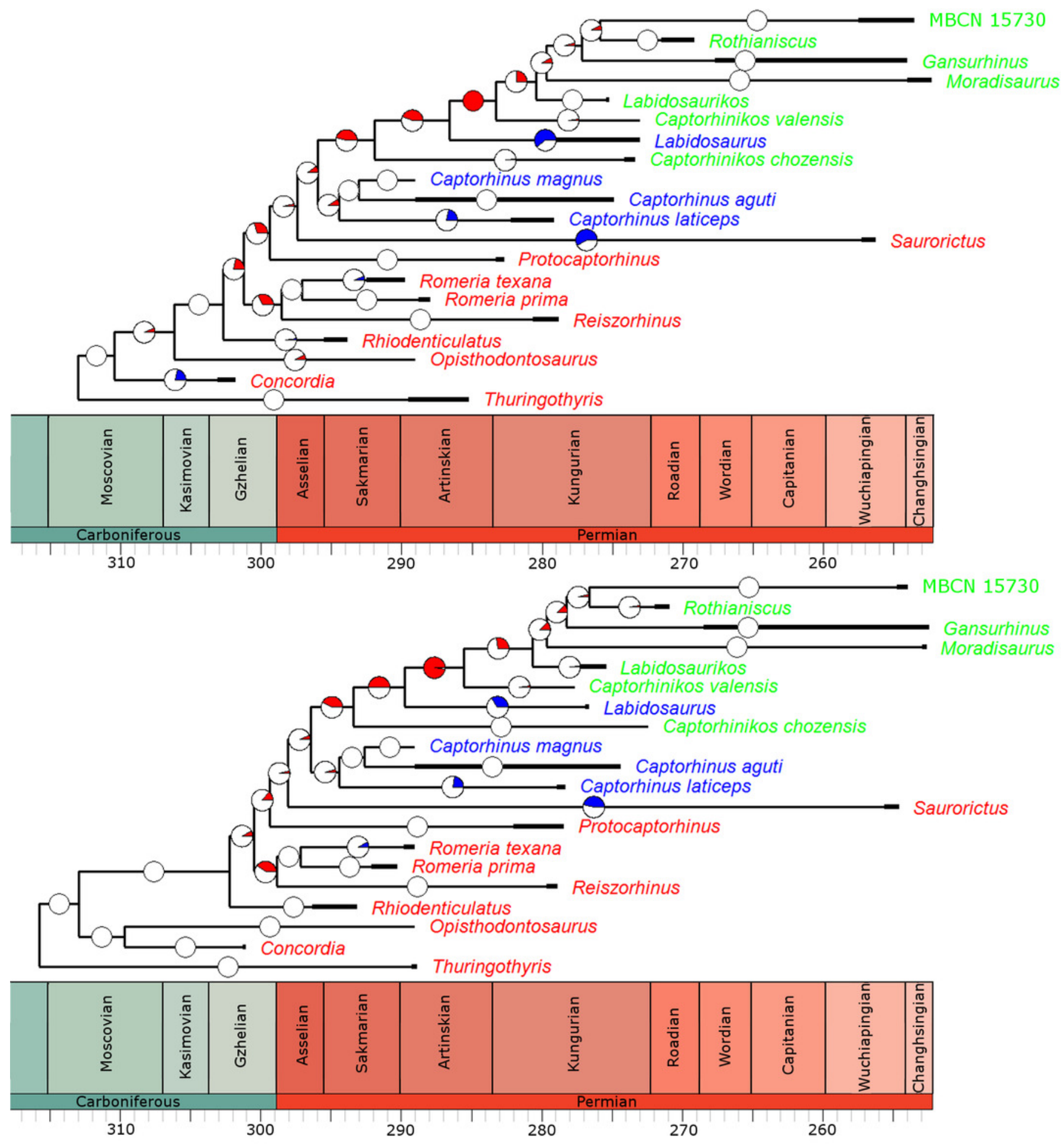


Figure 5

A comparison of the mean rates of evolution within each dietary regime.

(A) Histogram illustrating the mean rate of discrete character evolution calculate for each dietary regime in each of the 10,000 stochastic maps of dietary evolution; (B) Histogram illustrating the mean rate of discrete character evolution calculate for the herbivorous lineages compared to a random selection of branches with an equal sample size in each of the 10,000 stochastic maps of dietary evolution.

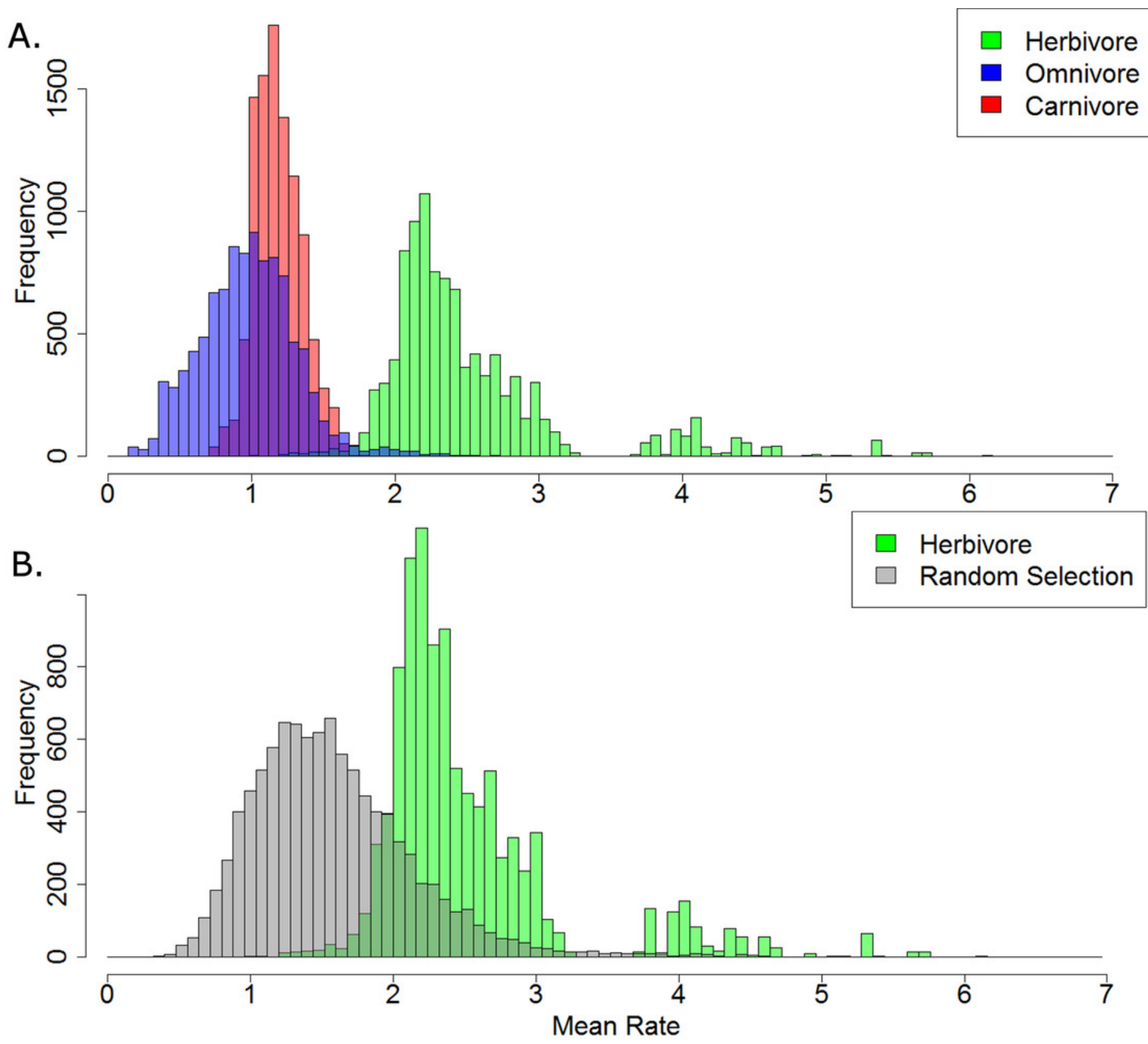


Figure 6

A comparison of the morphological distances between taxa within each dietary regime.

Histogram illustrating the mean MORD distance between each taxon in each each dietary regime in each of the 10,000 stochastic maps of dietary evolution.

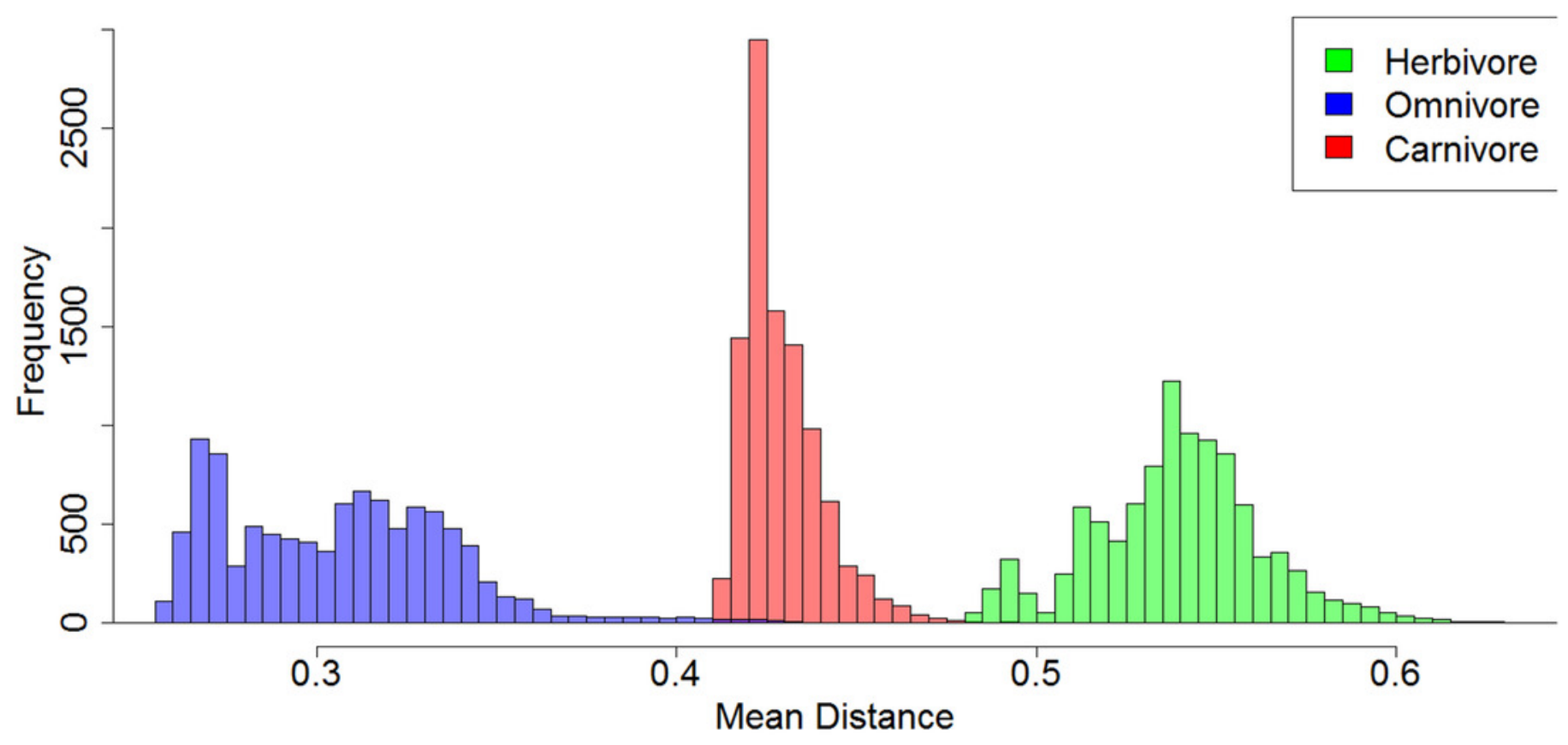




\section{Figure 7}

A comparison of disparity through time of the captorhinids in each dietary regime The disparity (sum of variances) calculated for all taxa within each dietary regime in each time bin. Values shown in the graph are the means of the values calculated in 10,000 stochastic maps of dietary evolution. The dashed line represents the mass extinction event dubbed Olson's Extinction. (A) Morphology along each branch calculated assuming a gradualist model of evolution; (B) Morphology along each branch calculated assuming a punctuated model of evolution. 

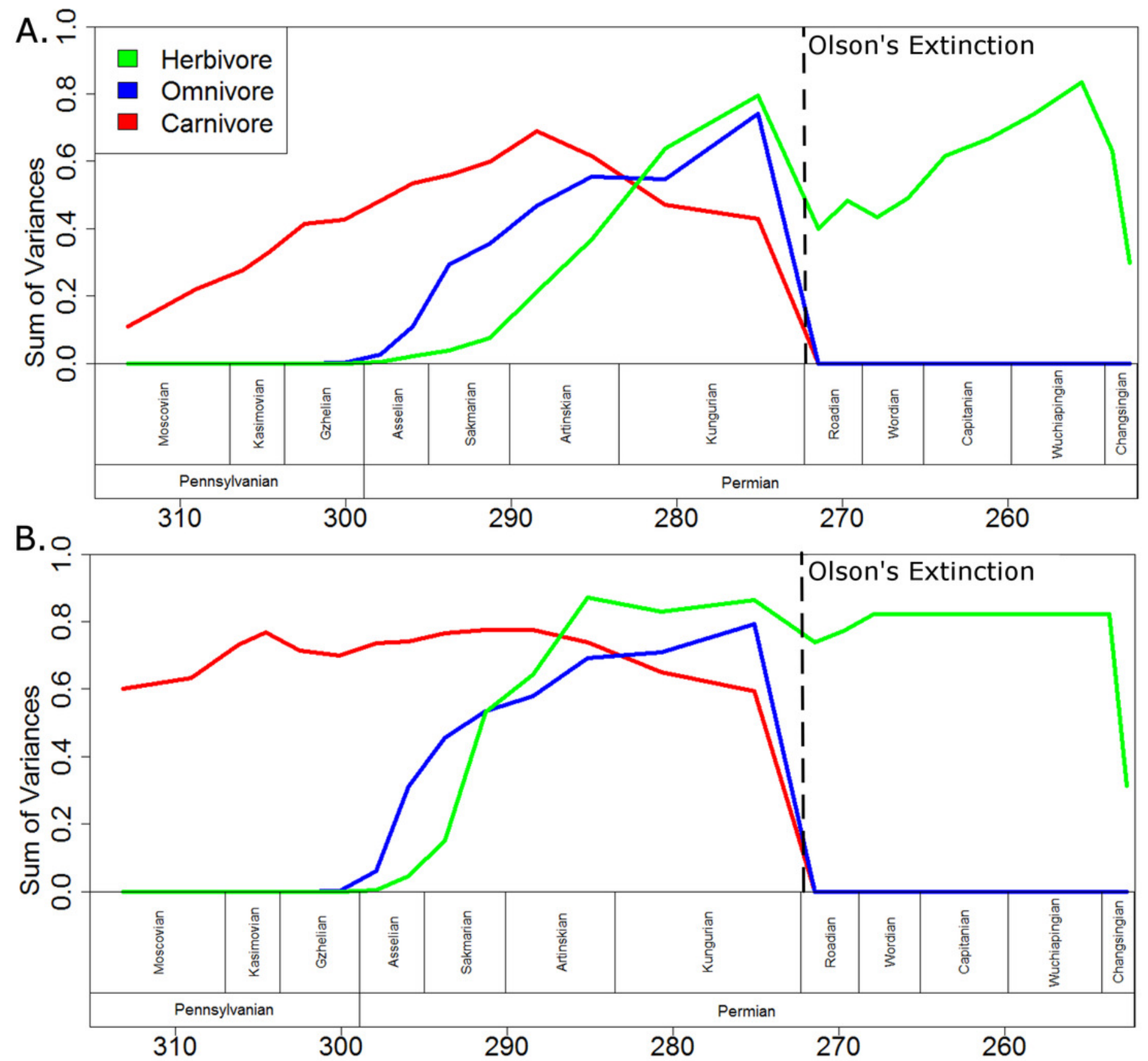
Figure 8

Lineage densities of captorhinids in each dietary regime

Boxplots indicating the distribution lineage densities of the captorhinids in each dietary regime, calculated in each of the 10,000 stochastic maps of dietary evolution.

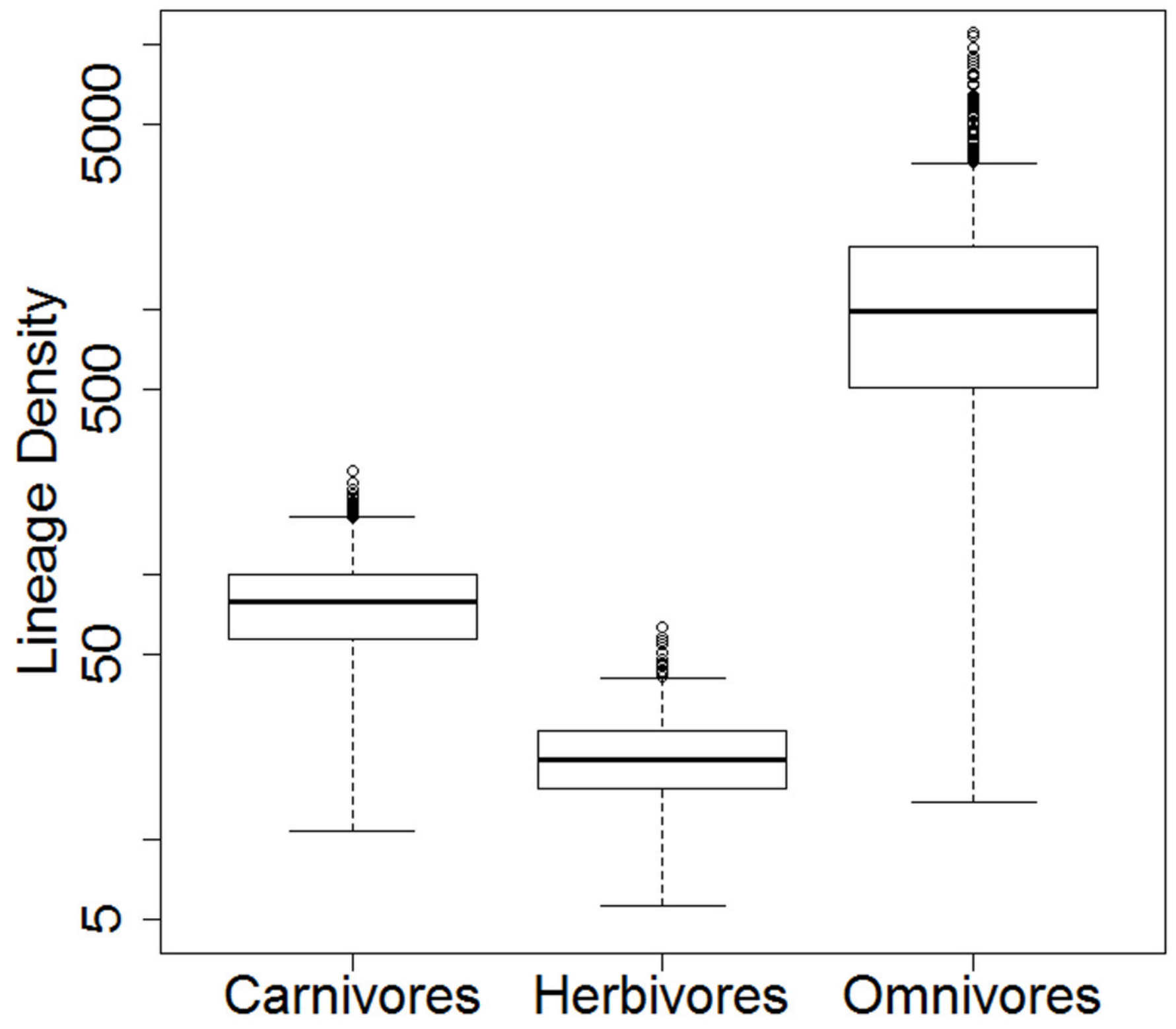




\section{Figure 9}

The proportion of characters within each skeletal region changing within each dietary regime

Boxplots illustrating the distribution of the proportions of character changes in each skeletal region occur in each dieatary regime, calculated in each of the 10,000 stochastic maps of dietary evolution. (A) Carnivores; (B) Omnivores; (C) Herbivores. 

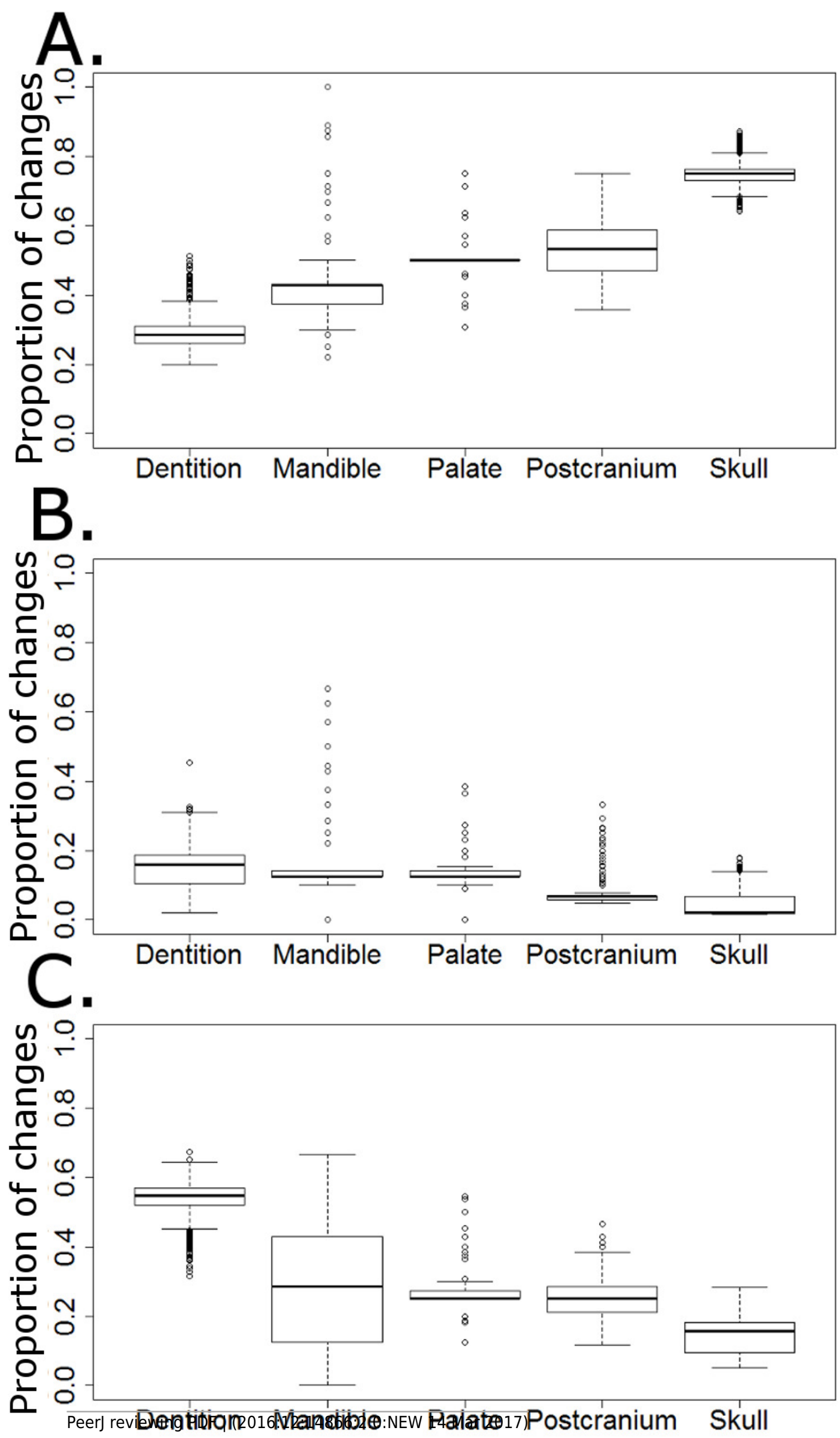


\section{Figure 10}

Phylomorphospace of captorhinids

The phylogeny of captorhinids plotted over principal coordinates 1 and 2 . Colours of lineages represent the die found to have the highest probability by the likelihood ancestral state reconstruction. Taxon labels - 1: Thuringothyris ; 2: Concordia ; 3: Opisthodontosaurus ; 4: Rhiodenticulatus ; 5: Reiszorhinus ; 6: Romeria prima ; 7: Romeria texana ; 8:

Protocaptorhinus ; 9: Saurorictus ; 10: Captorhinus laticeps ; 11: Captorhinus aguti ; 12: Captorhinus magnus ; 13: Captorhinikos chozensis ; 14: Labidosaurus ; 15: Captorhinikos valensis ; 16: Labidosaurikos ; 17: Moradisaurus ; 18: Gansurhinus ; 19: Rothianiscus ; 20: MBCN 15730.

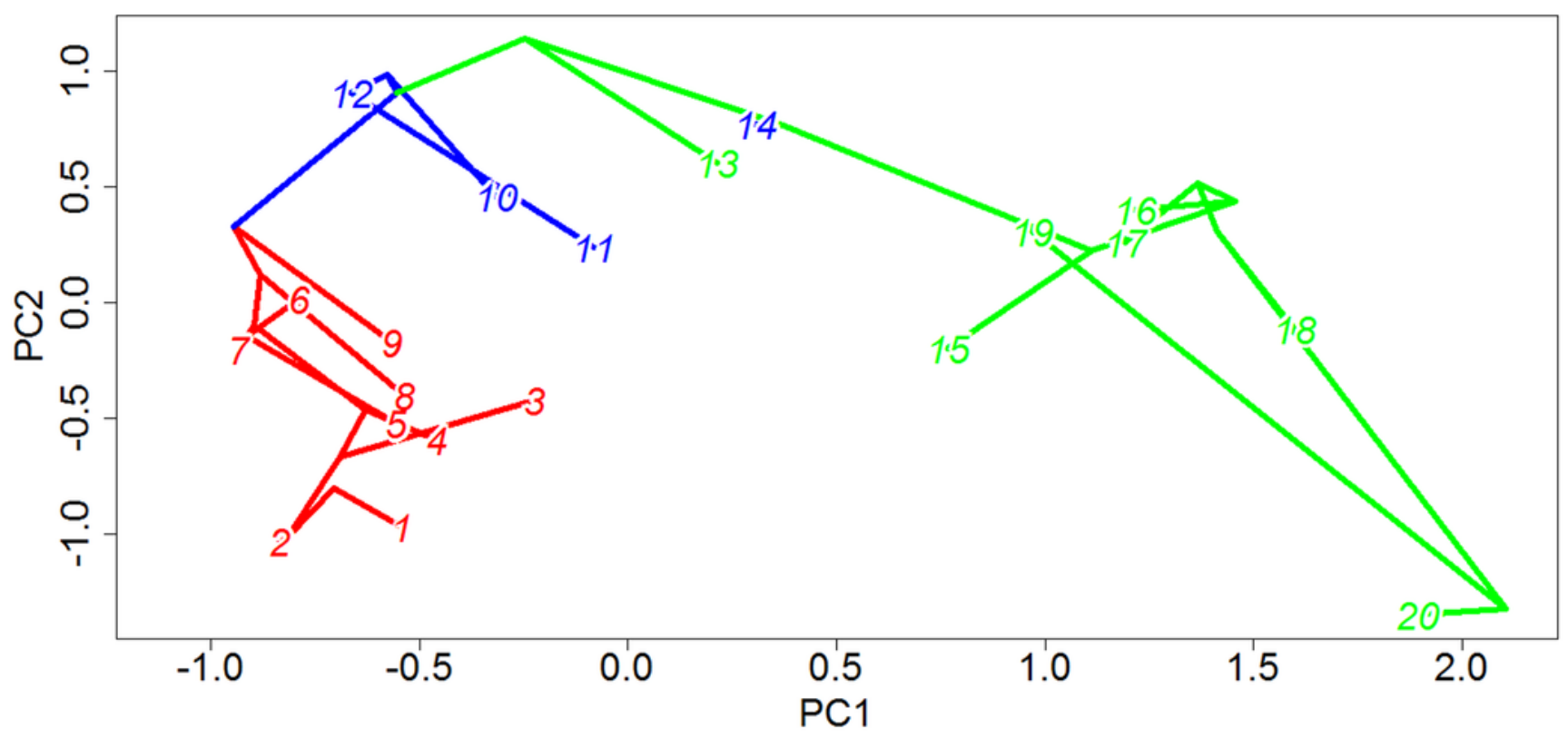

